\begin{tabular}{|c|c|c|} 
INTERNATIONAL JOURNAL OF \\
ORGANANIZATIONAL \\
IEADESHHIP
\end{tabular}

\title{
Effects of Fatherhood on Leadership Behaviour of Managers
}

\author{
Bernhard Stellner*
}

Faculty of Management and Economics, Mendel University Brno, Czech Republic

\section{Keywords: \\ Management behaviour, Leadership, Fatherhood, Parenthood, Work-life enrichment, Multiple roles}

\section{Received}

02 October 2021

Received in revised form

22 October 2021

Accepted

25 October 2021

\section{*Correspondence:}

bernhard.stellner@hotmail.com

\begin{abstract}
Becoming a father is a major life event for men and is accompanied by new role expectations and behavioural changes. While earlier research focused on the conflictual facets, more recent work-family enrichment theory emphasises the positive aspects of multiple roles. Previous quantitative and qualitative research has found that parenthood positively influences overall leadership and management behaviour at work. Our quantitative study uses a more granular definition of leadership behaviour with data from 157 male managers from Central Europe collected with a web-based survey. We find that 14 out of 15 transformational leadership behaviours (TLB) improve significantly with fatherhood. The individual behaviours supporting, recognizing, and developing progress the most. Only networking remains unaffected. Parental role enrichment outweighs conflict, and the resulting net effect correlates strongly with TLB. Also, parental role commitment and job level (position and number of subordinates) have a positive effect on TLB improvement. Parental role commitment and net enrichment show strong multicollinearity. Despite the positive effects of fatherhood on TLB in general, these decrease as the number of children increases, contradicting the intuition that "the more, the better". The findings should be considered in both managerial theory and practice as they concern the majority of men in leadership positions.
\end{abstract}

@CIKD Publishing

Becoming a father frequently involves taking over additional responsibilities in life that may change men's mental patterns and behaviours (Bleidorn et al., 2016; Graves et al., 2007; Jokela et al., 2009; Specht et al., 2011; van Scheppingen et al., 2016). Men who are both active as fathers and professionals have to find a new balance between the two worlds they are engaged in (Aaltio-Marjosola \& Lehtinen, 1998). These two worlds differ significantly in their requirements and expectations for managers. Work requires them to be emotionally controlled, while family members expect them to be emotionally open (Greenhaus \& Beutell, 1985). 
Taking care of others, feeling responsible, guiding others into autonomy, leading through changing environments, improvising, understanding, and motivating are attributes and behaviours that are valid for both fathers and leaders. At first glance, there seem to be similarities between parenthood and leadership as both domains require situational actions, empathy, attention, support, and motivation. However, it is also conceivable that this major life event completely bounces off from men in terms of their behaviour at work, fostered by the desire to keep family and work domains separated.

In recent years, the amount of research on the general linkages between family and work has grown significantly. Moreover, interdisciplinary collaboration between family research and management research evolves steadily (Edwards \& Rothbard, 2000; Jaskiewicz et al., 2017). Overall, there is considerable theoretical and empirical evidence that involvement in a multiplicity of roles results in outweighing benefits over costs regarding both physical and mental health (Barnett \& Hyde, 2001; Baruch \& Barnett, 1986; Greenhaus \& Powell, 2006). Hence, it is also possible to meet the demands of multiple domains (Ruderman et al., 2002) and benefit by multiplicity.

\section{Work-Family Enrichment and its Antecedents}

Initially, the effects of multiple roles on individuals were described with the help of role strain (scarcity) theory (Goode, 1960). Deducted from the economic principle of limited resources, also human beings allocate their limited resources among alternative ends. To maximise utility or minimise cost, humans seek to reduce the felt strain that is inevitably associated with a shortage. This role strain is the difficulty felt in fulfilling role obligations. It may express itself in reduced time, performance, and attention. Time and energy are finite resources that cannot expand and have to be allocated in an individual bargain. Therefore, if a manager attempts to fulfil the role of a father, he will lack resources to fulfil his managerial role and subsequently reduce performance. Goode's theory offers a rather pessimistic view on the effects of fatherhood on managers but already recognises that some role obligations drain less energy than others. However, later research has opened other perspectives on the possible benefits of multiple roles.

Not negating the negative effects of multiple roles, Sieber (1974) describes four positive outcomes of role accumulation: role privileges, overall status security, acquired resources, and enrichment of personality. Marks (1977) considers human involvement in social groups a positive, enriching, and vitalising impact. Activity in multiple roles is, therefore, an energyexpanding measure. Moreover, he argues that participation in one role can create rewards that positively influence other roles. Although Sieber (1974) and Marks (1977) had already provided preliminary work for a more holistic scarcity and accumulation theory, in 1985, Greenhaus and Beutell published a highly recognised paper focusing on a model for work-family conflict. They examine sources of conflict between family and work role. (Interrole) Conflict appears when the pressure in one domain is not compatible with pressure in another domain and can be timebased, strain-based, or behaviour-based. Especially male managers are claimed to face incompatible behavioural role expectations. Although the authors' work focuses on the conflictual perspective between multiple roles, they do not negate that there are also supportive factors (Greenhaus \& Beutell, 1985), a notion picked up later on by Greenhaus and Powell (2006). Barnett and Hyde (2001) point out that multiple roles are beneficial on a mental, 
physical and relational level. Yet, they argue that benefits depend on the quantity and quality of roles.

It was not until Greenhaus and Powell's (2006) seminal paper that the beneficial effects of multiple roles have been distilled into more precise elements and poured into a holistic theoretical framework. Besides that, they explain the direct and indirect mechanisms of interference between roles. As visualized in Figure 1, they claim that work and family have bidirectional sources of conflict and enrichment, but in a net view, they enrich each other. Thus, while conflict is a psychological stressor caused by incompatibility between roles, enrichment is a developmental phenomenon caused by a successful transfer of gains between roles.

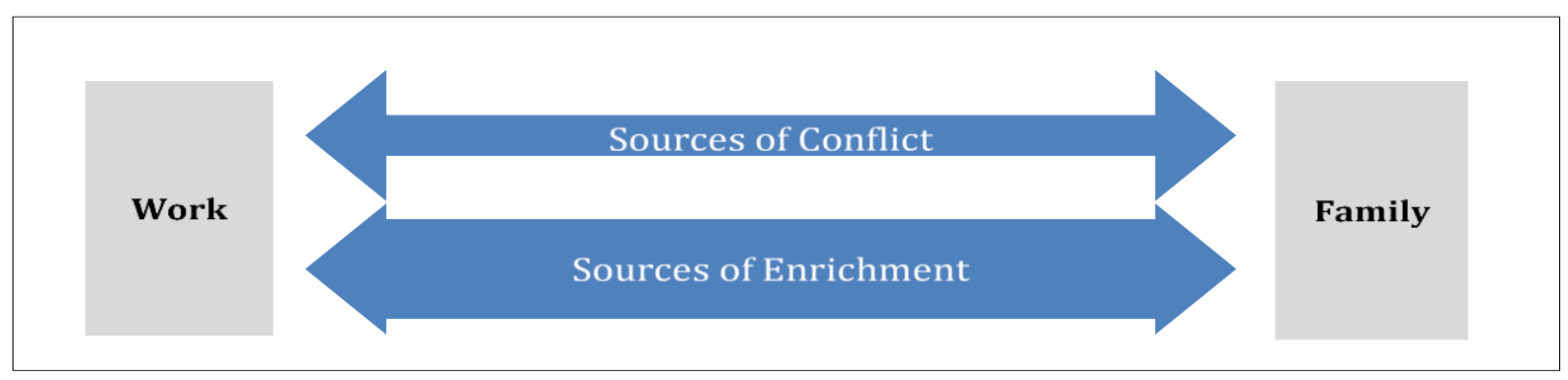

Figure 1. Simplified description of bidirectional work-life enrichment and conflicts (Greenhaus \& Powell, 2006)

Greenhaus and Powell (2006) highlight three general ways in which involvement in multiple roles generates benefits for individuals: addition, buffering, and the actual bidirectional workfamily enrichment. Addition and buffering refer to the phenomena that multiple roles can create life satisfaction by generating successes and balancing drawbacks. Both do not per se refer to a transfer of experience from one role to another. This transfer is described by work-family enrichment, "the extent to which experiences in one role improve the quality of life in the other role” (Greenhaus \& Powell, 2006, p. 72). They describe two pathways of enrichment: On the one hand, the instrumental path suggests that resources accumulated in one role can directly promote performance in another role. On the other hand, an indirect transfer, called affective path, describes the resource-based positive influence on emotions and good performance in one role, resulting in high performance in another role. Greenhaus and Powell identify five clusters of resources that are considered interdependent insofar as the acquisition of one resource may trigger the creation of others: 1) Skills and perspectives - Skills can be described as a set of abilities derived from experience in roles like task-related cognitive and interpersonal skills, coping, multitasking and general knowledge. Perspectives refer to an expanded world view by having experience in handling situations, understanding problems as well as respecting other opinions and backgrounds. 2) Psychological and physical resources - Roles can also contribute to generating mental and physical fitness by increased self-esteem, motivation, resilience, rigidity, optimism, hope, and exercise. 3) Social capital resources - Expressed by influence and information, social capital refers to the resources that may be generated by relationships with other individuals or societies. 4) Flexibility - Being able to set the timing, workload and place of a role, hence flexibility, is considered an effective resource as productivity in each role can be increased. 5) Material resources - Money, gifts or other fringe benefits like a company car represent the most obvious type of resources that can be generated in a role. 
Resources generated in one life domain lead to enhanced quality in other domains of life. Metaphorically speaking, the pie expands even though and indeed because one slice is already occupied (Greenhaus \& Brummelhuis, 2013; Greenhaus \& Powell, 2006; Lapierre et al., 2018). For male managers, this could mean that fatherhood is a kind of management training for the work domain (Carney, 2004).

\section{Previous Research}

Research in the context of management/leadership and the work-family framework has emphasised female managers. The benefits of parental roles for managerial women have been explored by Ruderman et al. (2002) by qualitative and quantitative results. They discover that interpersonal and task-related skills improve with motherhood. In general, they contribute to the literature by emphasising the positive sides of multiple roles and hence reduce the tenacious polarisation suggested by the scarcity theory. Graves et al. (2007) were the first scholars to apply the work-family enrichment theory by Greenhaus and Powell and find a significant correlation between parental role commitment and work performance of male and female managers. Graves et al. argue that this is triggered by the broad changes in psychological structures and behaviours induced by parenthood that lead to reduced self-focus, increased awareness for the needs of others, increased maturity, and responsibility. Moreover, they conclude that parents have higher pressure to provide for their children and perform better as they need to keep their jobs. Nevertheless, the used definition of work performance is still insufficient to conclude the implications on individual leadership behaviours. Similarly, Dumas and Stanko (2017) observe a positive influence of family role commitment on transformational leadership behaviour in a quantitative study. They argue that the needed skills for transformational leadership and the family role are similar. Amongst others, improved leadership is expressed by skills in change management, relationship management, taking over responsibility, creativity, helping, and developing others. Although using the Leadership Practice Inventory (LPI) captures 30 leadership items, they do not analyse them in detail. Female managers show stronger improvements than males. Also, in qualitative studies a positive link between fatherhood and generally increased management skills is found: Grau Grau (2017) confirms family-to-work enrichment theory by conducting and analysing semistructured interviews with 20 working men from Catalonia. Parts of the participants were top and middle managers. Some of them indicated that their (people) management skills have improved with fatherhood. This was especially true in the fields of sensitivity, patience, and responsibility. Still in line with the seminal models of Greenhaus and Powell, some working fathers also reported no enrichment at all. Nunes-Costa et al. (2020) also explain the positive effects of parenting experience on empathy and management skills. Based on multiple role theory and its follow-ups, they argue that increased human activity creates personal resources that improve management skills. Parents show higher levels of empathy than childless managers. Likewise, both genders benefit from significantly improved management skills when they have gained parental experience. Also, in other studies and popular press, raising children in a dedicated way is described as beneficial for developing leadership skills at work (Fischer \& Kotai-Szarka, 2006; Hansen, 2018).

Work and family domains are deeply interwoven. While early research focused on the conflictual aspects, scholars have later added the positive sides of multiple roles in their 
analyses. Accordingly, research has evolved from a static scarcity approach to holistic models of work-family enrichment, which consider that experiences can be transferred between roles and enrich each other. Likewise, the fatherhood image has evolved from a pure breadwinner role to an involved, nurturing role in which fathers actively participate in parental responsibilities (Cannito, 2020; Cunningham, 2008; Dermott \& Miller, 2015; Genesoni \& Tallandini, 2009). This increased commitment to the parental role, as well as any other form of role salience, has the potential to catalyse enrichment between work and family (Greenhaus \& Powell, 2006). Even though in aggregated form in terms of leadership behaviour, all recently conducted studies show that behavioural changes of managers induced by parenthood occur, mainly towards the positive side.

\section{Research Gap}

Despite the first solid steps of research with clear evidence pointing towards the beneficial effects of fatherhood, there remains the need to further break down leadership skills, understand which specific behaviours change, and consider control variables. Nunes-Costa et al. (2020) explicitly call for a more detailed consideration of management competences in further research. This paper contributes to the existing literature by working with a more granular leadership/management term and simultaneously testing for the influence of conflict, enrichment, and parental role commitment on transformational leadership. Closing this gap is also relevant for practice as managers and subordinates should anticipate and react to behavioural changes. Moreover, from a geographical point of view, no studies on the relations between parenthood and leadership behaviour focusing on Central Europe are known. To our knowledge, no quantitative study in the context of parenthood has dealt exclusively with male managers so far.

\section{Objectives}

This paper aims to verify the applicability of the work-family enrichment model for fathers who are in managerial positions. Furthermore, differences in the development of individual leadership behaviours and the moderating effects of conflict, enrichment, and parental role commitment shall be verified. Finally, we also seek to formulate recommendations for managerial and organisational practice as we believe that this topic lacks discussion in corporate and public contexts. It shall be noted that this objective explicitly does not aim for answering whether fathers generally are better or worse managers, but rather how an important life event and experience influences individual behaviours in the professional context.

\section{Hypotheses}

Previous research, both of quantitative and qualitative nature, has provided enough evidence that parenthood positively influences overall leadership and management behaviour. Greenhaus and Powell's (2006) work-family enrichment theory forms the conceptional basis to suppose improved leadership behaviour induced by fatherhood. They state that work-family enrichment happens in various fields by the following factors: skills and perspectives, psychological and physical resources, social capital resources, flexibility, and material resources. The first three have the potential to trigger improved leadership abilities. Additionally, by means of the affective path, positive mood gained in the parental role can enhance cognitive functioning, 
persistency, and task and social activity in the professional leadership role (Edwards \& Rothbard, 2000; Greenhaus \& Powell, 2006). We, therefore, expect leadership behaviour to change towards improvement along with all individual, clustered, and aggregated forms.

Hypothesis 1: Parental role experience of fathers improves their aggregated transformational leadership behaviour at work.

Hypothesis 2: Parental role experience of fathers improves their task-oriented transformational leadership behaviours at work.

Hypothesis 3: Parental role experience of fathers improves their relations-oriented transformational leadership behaviours at work.

Hypothesis 4: Parental role experience of fathers improves their change-oriented transformational leadership behaviours at work.

Hypothesis 5: Parental role experience of fathers improves their external-oriented transformational leadership behaviours at work.

Although there might also be a negative influence by sources of conflict (e.g., stress, sleep deprivation, overload, etc.), a net enrichment effect caused by multiple roles is expected (Greenhaus \& Powell, 2006).

Hypothesis 6: The degree of family-work enrichment outweighs the degree of family-work conflict for fathers in leadership positions.

Work-family enrichment theory describes that experiences gained in the parental role may improve the quality in the professional role (Greenhaus \& Powell, 2006). Therefore, besides the expectation that enrichment outweighs conflict as suggested by Greenhaus and Powell (Hypothesis 6), we also assume the residual (enrichment score minus conflict score) positively related to the change of aggregated transformational leadership behaviour. Therefore, acceptance of hypothesis 6 is a pre-condition for testing hypothesis 7.

Hypothesis 7: The residual of family-work interface ("net enrichment") positively correlates with improvement of aggregated transformational leadership behaviour.

High identification with the family and parental role reduces the behavioural boundaries between family and work domain. Moreover, commitment to a role increases the probability that transferable resources are generated. Thus, behaviours align across roles which could lead to an enrichment of the work domain. Previous studies on (female) managers provide evidence that family and parental role commitment are positively related to improved leadership skills (Dumas \& Stanko, 2017; Graves et al., 2007; Ruderman et al., 2002). We assume that this increased transfer of valuable skills and experiences to the work domain is also valid for male managers.

Hypothesis 8: Parental role commitment is positively related to aggregated transformational leadership behaviour.

\section{Methods}

\section{Design}

The present study follows an empirical-quantitative approach to verify or falsify the hypotheses formulated based on research of the body of literature. As it is mostly premised on existing 
theories, it has an explanatory character. Managers were asked via an anonymous online survey about their perceptions of the effects of fatherhood on their leadership behaviour.

\section{Measures}

During our survey and questionnaire, we processed four groups of variables that require a more detailed explanation: conflict, enrichment, parental role commitment, and transformational leadership behaviours.

(Interrole) conflict - happening when the pressure in one domain is incompatible with pressure in another domain - can be time-based, strain-based, and behaviour-based (Greenhaus \& Beutell, 1985). Carlson et al. (2006) developed a scale to measure work-family conflict, which was later refined by Matthews et al. (2010) using factor analysis, and finally consists of six statements that capture both directions and the three types of conflict. Statements like "Behavior that is effective and necessary for me at home would be counterproductive at work." are meant to be answered using a 5-point Likert scale ranging from "strongly disagree" to "strongly agree" (Carlson et al., 2006; Matthews et al., 2010).

Similarly, for enrichment Carlson (2006) developed a self-perception questionnaire that captures both the family-to-work and work-to-family perspective from a directional point of view. Regarding sources of enrichment, the perspectives development, affect, capital, and efficiency are covered. A shortened version consists of overall six statements like "Family to work development helps me acquire skills and this helps me be a better worker." which are answered with a 5-point Likert scale ranging from "strongly disagree" to "strongly agree" (Kacmar et al., 2014).

Parental role commitment (PRC) is the willingness and intention to invest time, personal resources in the parental role and its development. A widely recognised and used instrument to measure parental role commitment can be found within the Life Role Salience Scales (LRSS) by Amatea et al. (1986). Altogether five statements like "I expect to be very involved in the day-to-day matters of rearing children of my own." are answered using a 5-point Likert scale ranging from "disagree" to "agree" (Amatea et al., 1986).

To increase consistency for the respondents, we used the answer options "agree" (1)/"rather agree" (2)/“"neutral" (3)/“rather disagree" (4) and "disagree" (5) for the Likert scales for conflict, enrichment, and PRC. For both conflict and enrichment, we captured the direction family-to-work only.

Keeping in mind that management (subject-oriented) and leadership (people-oriented) are regarded as different concepts by some scholars (Kotter, 1990; Kotterman, 2006; Zaleznik, 1977), we focused on assessing transformational leadership, as it is regarded superior (Bass, 1990; Dumas \& Stanko, 2017). Transformational leadership behaviour (TLB) is measured with the taxonomy provided by Yukl (2012), who builds on a meta-categorisation of existing and recognised questionnaires. It comprises four clusters of behaviours and a total of fifteen individual behaviours:

- $\quad$ Task-oriented TLB - clarifying, planning, monitoring, and problem-solving

- Relations-oriented TLB - supporting, developing, recognising, and empowering

- Change-oriented TLB - advocating change, envisioning change, encouraging innovation, and facilitating collective learning

- External-oriented TLB - networking, external monitoring, and representing 
Exemplarily, Yukl's description of the individual behaviour "supporting", the leader "shows concern for the needs and feelings of individual members; provides support and encouragement when there is a difficult or stressful task, and expresses confidence members can successfully complete it", shall be stated (Yukl, 2012, p. 84). Although Yukl does not provide a final questionnaire, the descriptive statements appear suitable to confront a survey participant with and ask for an assessment (of the change) of own behaviour after fatherhood. We used a 5-point Likert scale ranging from "strongly improved" (1) over "unchanged" (3) to "strongly worsened" (5), plus the answer option "not applicable". Consequently, values below 3 indicate behavioural improvements. By averaging scores of individual leadership behaviours, we created clustered TLB and aggregated TLB scores.

\section{Data Collection and Sample}

Besides the main variables, we controlled for other variables that could affect managers' parental and professional experiences orienting on the most common control variables in leadership research (Bernerth et al., 2018). Age was collected to account for experience and difference in perception. Household income could influence leaders' ability to compensate for lack of time by outsourcing duties and impact self-esteem and perception (Dumas \& Stanko, 2017). Number of children was collected to account for intensifying or adverse effects of high numbers of children on leadership behaviours. Level of education could influence the ability and approaches to evaluate change in a leadership setting. Job position and span of control may also directly influence leadership requirements and behaviours. We also collected work hours and hours with children as they could influence how leadership is "lived" (Dumas \& Stanko, 2017). Additionally, variables like country of residence and sector were collected to better understand the sample. Participants' race was neither asked for nor collected.

The relevant population (Central European male managers with at least one direct projectrelated subordinate) is not precisely determinable but most likely exceeds 10 million individuals. As prior research was unavailable for estimating effect sizes, we determined the sample size with a more general approach. The most complicated analyses in the current study consist of linear regression models with two main predictors and eight control variables. With expected confidence levels of $95 \%$ and a margin of error of $8 \%$, a sample size of 150 is sufficient. Other common rules of thumb propose ten subjects per predictor (here: 110 participants).

Data collection via the platform SurveyMonkey lasted from March to May 2021 and taped the author's private and professional network, as well as a professional panel. The questionnaire consisted of 40 questions and was provided in German and English language. IP address tracking was activated solely to enable cross-checking of data quality. The survey interface had a graphically appealing design and was compatible with all conventional browser settings on mobile and desktop devices. All participants voluntarily contributed and were informed that they could withdraw from the survey at any time. At the beginning of the questionnaire, screening questions were set to filter out respondents who did not meet the target criteria. During data cleansing, responses with inconsistent or unrealistically fast answers were eliminated from the data set. Overall, 157 managers provided a full data set that could be processed. We thus exceeded the minimum sample size. 


\section{Results}

\section{Reliability}

Table 1 shows that variables had acceptable Cronbach alphas considering the small number of items which causes a known bias towards lower reliability coefficients (Cortina, 1993).

Table 1

Cronbach $\alpha$ Coefficients

\begin{tabular}{|c|c|c|c|}
\hline Variable & $n$ & Cronbach $\alpha$ & Items \\
\hline Change in Aggregated TLB & 157 & .87 & 15 \\
\hline Change in Task-Oriented TLB & 157 & .77 & 4 \\
\hline Change in Relations-Oriented TLB & 157 & .74 & 4 \\
\hline Change in Change-Oriented TLB & 157 & .63 & 4 \\
\hline Change in External-Oriented TLB & 157 & .68 & 3 \\
\hline Source of Enrichment & 157 & .73 & 3 \\
\hline Source of Conflict & 157 & .67 & 3 \\
\hline Parental Role Commitment & 157 & .69 & 5 \\
\hline
\end{tabular}

Note. $\mathrm{n}=157 . \mathrm{TLB}=$ Transformational Leadership Behaviour.

\section{Descriptive Statistics}

The overall final sample was entirely male, from Germany (57.3\%) and Austria (37.6\%), held degree of higher education (66.2\%), had a monthly household income ranging from $€ 3.000$ to $€ 5.999$ (50.0\%), was married or in a registered partnership (82.87\%), was an owner/CEO $(31.9 \%)$ or worked in middle management $(35.0 \%)$, and had one or two children $(80.3 \%)$. The mean age of the sample was 42 years and therefore conformed to other studies (Graves et al., 2007; Nunes-Costa et al., 2020; Ruderman et al., 2002) and general averages in European countries. Ages ranged between 20 and 79 years. Participants had an average of 61.4 subordinates and worked 48.20 hours per week on average. We covered representatives from all relevant industry sectors. The mean values and standard deviations of the key variables are displayed in Table 2.

Table 2

Descriptive Statistics of Study Variables for Leaders and Employees

\begin{tabular}{|c|c|c|c|c|}
\hline \multirow[b]{2}{*}{ Variable } & \multicolumn{4}{|c|}{ Leaders $(n=157)$} \\
\hline & $\mathrm{n}$ & Missing & $M$ & $S D$ \\
\hline Change in Aggregated TLB & 157 & 0 & 2.41 & 0.50 \\
\hline Change in Task-Oriented TLB & 156 & 1 & 2.34 & 0.67 \\
\hline Change in Relations-Oriented TLB & 157 & 0 & 2.15 & 0.65 \\
\hline Change in Change-Oriented TLB & 157 & 0 & 2.44 & 0.57 \\
\hline Change in External-Oriented TLB & 157 & 0 & 2.79 & 0.75 \\
\hline Source of Enrichment & 157 & 0 & 1.89 & 0.76 \\
\hline Source of Conflict & 157 & 0 & 3.23 & 0.93 \\
\hline Net Enrichment & 157 & 0 & -1.34 & 1.40 \\
\hline Parental Role Commitment & 157 & 0 & 2.21 & 0.78 \\
\hline
\end{tabular}

Note. $\mathrm{n}=157 . \mathrm{SD}=$ Standard Deviation, $\mathrm{TLB}=$ Transformational Leadership Behaviour.

\section{Hypotheses Testing}

Hypotheses 1 through 5 were evaluated with a series of Wilcoxon signed-rank tests to determine if responses on perceived change of behaviours were significantly different from a given value. The null hypotheses were the value 3, which was the response option for "unchanged" TLB. Lower responses indicate behaviours that improved while higher ones imply worsening.

Hypothesis 1 concerned the change in aggregated TLB. We observed that on average leaders' evaluation $(M=2.41)$ was significantly lower than 3 ("unchanged") $(Z=-9.82, p<$ .001 ) and closer to 2 ("slightly improved"). Figure 2 shows that nearly all of the leaders consider their average leadership behaviour to have improved. Hypothesis 1 is accepted. 


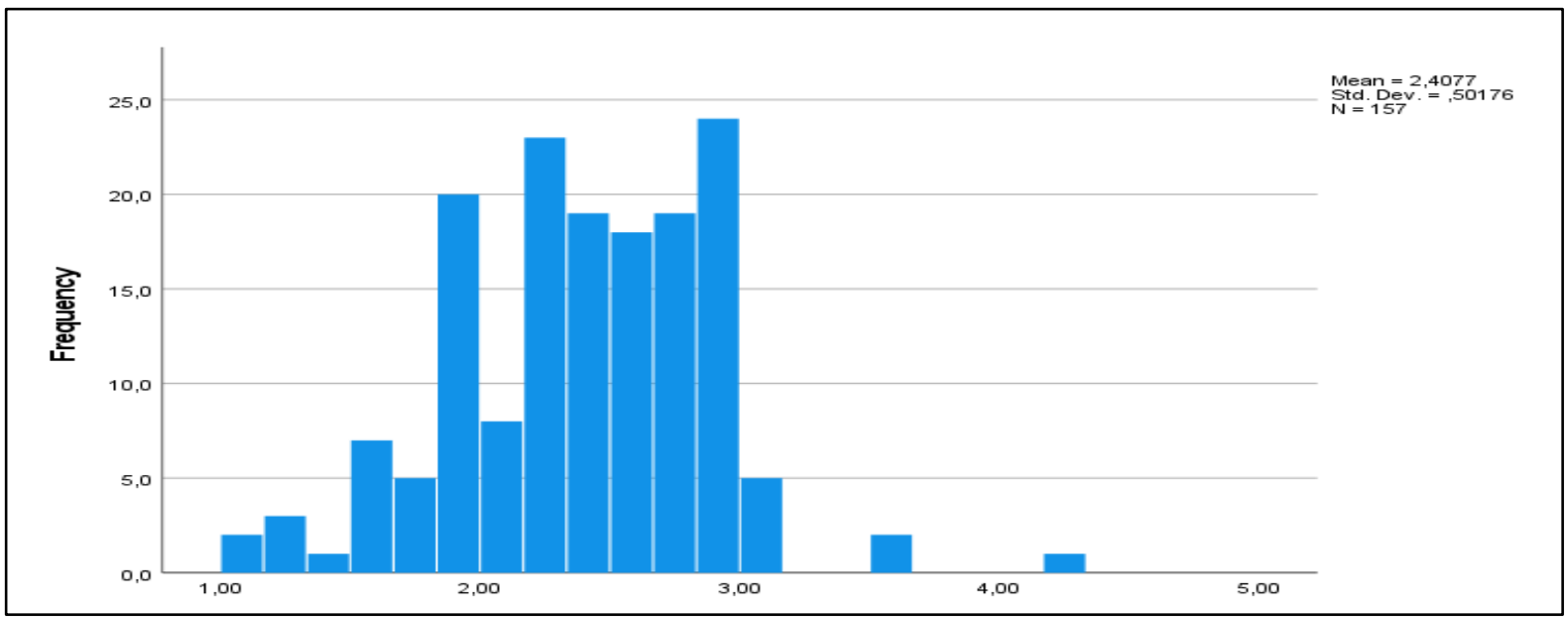

Figure 2. Aggregated TLB of leaders

Similarly, the clusters task-oriented $(M=2.34, Z=-8.71, p<.001)$, relations-oriented $(M=$ 2.15, $Z=-9.88, p<.001)$ and change-oriented $(M=2.44, Z=-8.83, p<.001)$ with all their individual behaviours were perceived to have improvement significantly being closer to "slightly improved". The strongest improvements occur within supporting, recognizing, and developing. Hypotheses 2, 3 and 4 are therefore accepted.

For external-oriented TLB, we also observed a significant change towards improvement ( $M$ $=2.79, Z=-3.41, p<.001$ ), but the absolute magnitude of improvement is only modest. Change in external-oriented TLB was the only variable in which not all individual behaviours were significantly different from "unchanged". Networking even pointed towards worsening. Notwithstanding the above, hypothesis 5 is accepted. Mean values and significance levels for all tested TLB are displayed in Table 3.

Table 3

Perceived Changes in Leadership Behaviour

\begin{tabular}{|c|c|c|c|}
\hline Variable & $M$ & $Z$ & $p$ \\
\hline Aggregated TLB & 2.41 & -9.83 & $<.001 * * *$ \\
\hline Task-Oriented TLB & 2.34 & -8.71 & $<.001 * * *$ \\
\hline Planning & 2.26 & -8.15 & $<.001 * * *$ \\
\hline Clarifying & 2.29 & -7.15 & $<.001 * * *$ \\
\hline Monitoring & 2.54 & -5.93 & $<.001 * * *$ \\
\hline Problem-Solving & 2.28 & -7.65 & $<.001 * * *$ \\
\hline Relations-Oriented TLB & 2.15 & -9.88 & $<.001 * * *$ \\
\hline Supporting & 2.00 & -8.92 & $<.001 * * *$ \\
\hline Recognizing & 2.15 & -8.37 & $<.001 * * *$ \\
\hline Developing & 2.22 & -8.23 & $<.001 * * *$ \\
\hline Empowering & 2.24 & -8.42 & $<.001 * * *$ \\
\hline Change-Oriented TLB & 2.44 & .8 .83 & $<.001 * * *$ \\
\hline Advocating Change & 2.38 & -7.37 & $<.001 * * *$ \\
\hline Envisioning Change & 2.52 & -6.07 & $<.001 * * *$ \\
\hline Encouraging Innovation & 2.36 & -7.48 & $<.001 * * *$ \\
\hline Facilitating Collective Learning & 2.52 & -6.39 & $<.001 * * *$ \\
\hline External-Oriented TLB & 2.79 & -3.41 & $<.001 * * *$ \\
\hline Networking & 3.07 & -0.54 & .592 \\
\hline External Monitoring & 2.77 & -3.19 & $.001 * * *$ \\
\hline Representing & 2.58 & -5.45 & $<.001 * * *$ \\
\hline
\end{tabular}

Note. $\mathrm{n}=157 . * \mathrm{p}<.05, * * \mathrm{p}<.01$, *** $\mathrm{p}<.001 . \mathrm{TLB}=$ Transformational Leadership Behaviour. Lower values indicate improvement, higher responses indicate worsening. Wilcoxon signed rank tests used to determine significant differences from 3 ("unchanged"). 
Hypothesis 6 examined if managers viewed fatherhood as a source of enrichment at work, or rather a source of conflict with their professional life. Another Wilcoxon signed-rank test was used, but this time the two ratings were tested against one another rather than against a set value. Leaders view fatherhood as a bigger source of enrichment $(M=1.89)$ than it is a source of conflict $(M=3.23)$. This difference was shown to be statistically significant $(Z=-8.82, p<$ $.001)$. Hypothesis 6 is accepted.

Consecutively, we tested whether aggregated TLB was related to net enrichment (hypothesis 7) and PRC (hypothesis 8) with Pearson correlation coefficients. Aggregated TLB improvement showed a moderate positive correlation with net enrichment $(r(157)=.35, p<.001)$. Notably, within net enrichment the variable conflict has no significant correlation with TLB. For PRC $(r(157)=.20, p=.011)$, we noted a small to medium positive relation with TLB. Additionally, strong multicollinearity between net enrichment and PRC $(r(157)=.50, p<.001)$ was observed, whereby the effect of conflict is stronger $(r(157)=-.51, p<0.001)$ than the effect of enrichment $(r(157)=.30, p<0.001)$. Hypotheses 7 and 8 are both accepted.

\section{Regression Analysis}

After testing all hypotheses, we ran a set of linear regressions to gain the fullest possible understanding of the relationship between net enrichment, PRC, control variables, and change in TLB. We analysed TLB down to the clustered leadership behaviours only as individual behaviours were collected on an ordinal scale. Coding of the variables was adapted to facilitate intuitive interpretation: A positive $\beta$ between TLB and a variable means that a higher score of the variable positively influences TLB (improvement). In SPSS, the method "Enter" was used to include the independent variables in the regression analysis, meaning that all variables in a block are considered in a single step.

As shown in Table 4, the regression models for change in aggregated TLB $(F(10,146)=$ $\left.4.82, p<.001, R^{2}=.25\right)$, change in task-oriented TLB $\left(F(10,145)=5.86, p<.001, R^{2}=.29\right)$, change in relation-oriented TLB $\left(F(10,146)=2.74, p<.01, R^{2}=.16\right)$ and change in changeoriented TLB $\left(F(10,146)=3.55, p<.001, R^{2}=.20\right)$ were all significant and accounted for between $16 \%$ to $29 \%$ of variance in the TLB outcome variables. However, the regression model predicting change in external-oriented TLB was not significant $\left(F(10,146)=1.40, p=.18, R^{2}\right.$ $=.09$ ). As we found from analysis of hypotheses 5 , this cluster has the smallest difference from unchanged behaviour.

In most significant models, net enrichment was a statistically significant predictor of the outcome with $\beta$ ranging from .24 to .28 . Higher net enrichment corresponds to improved leadership behaviour. The only exception was change in relation-oriented TLB where net enrichment was only significant at the $8 \%$ level with $\beta=.16$. Conversely, PRC was only a significant predictor of improvement in relation-oriented TLB $(\beta=.19, p=.04)$. Nevertheless, the strong multicollinearity between net enrichment and PRC $(r(157)=.50, p<.001)$ makes it difficult to precisely assign predictive strength between the two variables. Alternately leaving out net enrichment and PRC showed that the variables may substitute each other in their predictive power.

Some control variables were also significant predictors in the regression model. Education was a significant predictor of change in external-oriented TLB $(\beta=-.20, p=.02)$. Higher levels of education lead to reduced improvement. Current position was a significant predictor of 
change in aggregated TLB $(\beta=.22, p=.01)$, task-oriented TLB $(\beta=.31, p<.001)$, and changeoriented TLB $(\beta=.26, p=.002)$. For these clusters, a higher position corresponds with improved leadership behaviours. Lastly, number of subordinates was a significant predictor of change in aggregated TLB $(\beta=.15, p=.04)$ and in relation-oriented TLB $(\beta=.18, p=.03)$. On average, a higher number of subordinates leads to higher improvement of aggregated and relation-oriented TLB. Lastly, Number of children was a significant predictor of change in aggregated TLB $(\beta=-.18, p=.02)$ and task-oriented TLB $(\beta=-.24, p=.001)$. This is especially interesting as our general assumption that children lead to improved leadership behaviour holds true (as seen in H1 to H5) but seems to have an important limitation in terms of the number of children. High numbers of children lead to reduced improvement of leadership behaviours. Within the sample, 58 participants had one child and an average aggregated transformational leadership score of 2.39, whereas 27 participants had three children with a score of 2.51. Age of the managers, working hours, relationship status, and weekly hours spent with children have no statistically significant predictive power.

Table 4

Prediction of Change in Transformational Leadership Behaviours - Leaders

\begin{tabular}{|c|c|c|c|c|c|c|c|c|}
\hline Outcome Variable & $B$ & $S E$ & $\beta$ & $t$ & $F$ & $d f$ & $p$ & $R^{2}$ \\
\hline Aggregated TLB & & & & & 4.82 & 10.146 & $<.001$ & .25 \\
\hline Constant & 1.17 & .56 & & 2.10 & & & .04 & \\
\hline Net Enrichment & 0.10 & .03 & .27 & 3.23 & & & .002 & \\
\hline PRC & 0.07 & .06 & .10 & 1.18 & & & .24 & \\
\hline Education & -0.04 & .03 & -.12 & -1.62 & & & .11 & \\
\hline Working Hours & 0.00 & .00 & .07 & 0.85 & & & .40 & \\
\hline Relationship Status & 0.13 & .15 & .07 & 0.86 & & & .39 & \\
\hline Current Position & 0.12 & .04 & .22 & 2.66 & & & .01 & \\
\hline Number Children & -0.11 & .05 & -.18 & -2.39 & & & .02 & \\
\hline Subordinates & 0.00 & .00 & .15 & 2.04 & & & .04 & \\
\hline Hours with Children & 0.00 & .00 & .07 & 0.93 & & & .35 & \\
\hline Age & 0.00 & .00 & .05 & 0.58 & & & .56 & \\
\hline Task-Oriented & & & & & 5.86 & 10.145 & $<.001$ & .29 \\
\hline Constant & 1.35 & .72 & & 1.87 & & & .06 & \\
\hline Net Enrichment & 0.14 & .04 & .28 & 3.44 & & & .001 & \\
\hline PRC & 0.05 & .07 & .05 & 0.63 & & & .53 & \\
\hline Education & -0.03 & .03 & -.06 & -0.76 & & & .45 & \\
\hline Working Hours & 0.00 & .00 & .01 & 0.17 & & & .87 & \\
\hline Relationship Status & 0.14 & .19 & .05 & 0.72 & & & .47 & \\
\hline Current Position & 0.23 & .06 & .31 & 3.87 & & & $<.001$ & \\
\hline Number Children & -0.20 & .06 & -.24 & -3.29 & & & .001 & \\
\hline Subordinates & 0.00 & .00 & .12 & 1.60 & & & .11 & \\
\hline Hours with Children & 0.00 & .00 & .04 & 0.52 & & & .61 & \\
\hline Age & 0.00 & .01 & .01 & 0.17 & & & .87 & \\
\hline Relation-Oriented & & & & & 2.74 & 10. 146 & $<.01$ & .16 \\
\hline Constant & 0.26 & .76 & & 0.35 & & & .73 & \\
\hline Net Enrichment & 0.07 & .04 & .16 & 1.75 & & & .08 & \\
\hline PRC & 0.16 & .08 & .19 & 2.10 & & & .04 & \\
\hline Education & 0.00 & .04 & .00 & 0.05 & & & .96 & \\
\hline Working Hours & 0.00 & .01 & .07 & 0.86 & & & .39 & \\
\hline Relationship Status & 0.10 & .20 & .04 & 0.48 & & & .63 & \\
\hline Current Position & 0.06 & .06 & .09 & 1.02 & & & .32 & \\
\hline Number Children & -0.10 & .06 & -.12 & -1.51 & & & .13 & \\
\hline Subordinates & 0.00 & .00 & .18 & 2.20 & & & .03 & \\
\hline Hours with Children & 0.00 & .00 & .03 & 0.33 & & & .74 & \\
\hline Age & 0.00 & 0.00 & .07 & 0.79 & & & .43 & \\
\hline
\end{tabular}




\begin{tabular}{|c|c|c|c|c|c|c|c|c|}
\hline Outcome Variable & $B$ & $S E$ & $\beta$ & $t$ & $F$ & $d f$ & $p$ & $R^{2}$ \\
\hline Change-Oriented & & & & & 3.55 & 10.146 & $<.001$ & .20 \\
\hline Constant & 1.08 & .65 & & 1.65 & & & .10 & \\
\hline Net Enrichment & 0.10 & .04 & .24 & 2.71 & & & .001 & \\
\hline PRC & 0.01 & .07 & .01 & 0.15 & & & .88 & \\
\hline Education & -0.06 & .03 & -.16 & -2.05 & & & .04 & \\
\hline Working Hours & 0.00 & .00 & .02 & 0.22 & & & .82 & \\
\hline Relationship Status & 0.22 & .17 & .10 & 1.30 & & & .20 & \\
\hline Current Position & 0.16 & .05 & .26 & 3.10 & & & .002 & \\
\hline Number Children & -0.08 & .06 & -.12 & -1.49 & & & .14 & \\
\hline Subordinates & 0.00 & .00 & .07 & 0.92 & & & .36 & \\
\hline Hours with Children & 0.01 & .00 & .14 & 1.72 & & & .09 & \\
\hline Age & 0.01 & .01 & .11 & 1.25 & & & .21 & \\
\hline External-Oriented & & & & & 1.40 & 10. 146 & .18 & .09 \\
\hline Constant & 2.10 & .92 & & 2.29 & & & .02 & \\
\hline Net Enrichment & 0.08 & .05 & .14 & 1.51 & & & .13 & \\
\hline PRC & 0.06 & .09 & .06 & 0.63 & & & .53 & \\
\hline Education & -0.10 & .04 & -.20 & -2.37 & & & .02 & \\
\hline Working Hours & 0.01 & .01 & .09 & 1.02 & & & .31 & \\
\hline Relationship Status & 0.04 & .24 & .01 & 0.15 & & & .88 & \\
\hline Current Position & 0.00 & .07 & .00 & 0.03 & & & .98 & \\
\hline Number Children & -0.06 & .08 & -.07 & -0.78 & & & .44 & \\
\hline Subordinates & 0.00 & .00 & .11 & 1.29 & & & .20 & \\
\hline Hours with Children & 0.00 & .01 & .04 & 0.52 & & & .60 & \\
\hline Age & -0.00 & .01 & -.03 & -0.29 & & & .78 & \\
\hline
\end{tabular}

Note. $\mathrm{n}$ for all 156 or 155 . TLB $=$ Transformational Leadership Behaviour, PRC $=$ Parental Role Commitment. Statistically significant predictors and $\beta$ values are shown in bold.

\section{Discussion}

\section{Contribution}

In general, there is sufficient evidence for the positive effect of fatherhood on transformational leadership behaviours. Leaders tend to view fatherhood and time with their family as a net benefit to their professional life. Keeping in mind that there is no discussion on this topic in managerial practice, we argue that this finding is also of high practical relevance. Leadership behaviour may be formed by many other conditions like education, culture, situation, and motivation, but the mere statement by most survey participants that also fatherhood improves leadership behaviours adds an important component to understand what could make a good male manager.

External-oriented leadership behaviour shows the smallest deviation towards improvement. Within this cluster, networking even tends to be nearly unchanged. We expect that managers lack the time or willingness to devote time to participate in professional or extra-professional events that could expand their network. Nevertheless, we found no statistically significant correlation between networking and the variables conflict, working hours, hours with children, or the number of children. Also, external monitoring, which means that leaders keep their eyes open to be aware of changes and events outside the organisation, is weakly affected by fatherhood. Similar to networking, we assume that relevant improvements do not occur due to time and attention constraints.

Net enrichment is a significant predictor of change in aggregated, task-oriented and changeoriented transformational leadership behaviour. Fatherhood-induced conflict does exist, but it does not influence leadership behaviour. Parental role commitment is a significant predictor of relation-oriented transformational leadership behaviour. Moreover, transformational leadership improvement decreases with higher numbers of children, which is counterintuitive with respect 
to our general findings. We reason that the positive effects of parental experience are not multiplied with more children but rather overlapped by conflicts and overload.

From the view of managerial practice, a rigorous separation of family and work domain does not necessarily lead to the maximisation of human potentials. This is at least valid for our research subjects of male managers with children and the direction of the family to work. It, therefore, needs to be discussed whether blurring boundaries between family and work or other company policies that encourage males to devote time and energy to roles outside work lead to an improvement. At a very practical level, organisations could share and explain results of similar studies, grant parents extra holiday, provide day-care, organise family events to strengthen pride, and discourage long, inflexible working hours. Most importantly, expectant fathers need to be made aware of the changes in their leadership behaviour and be coached. Once managers are informed about the positive effects of the parenting experience, they can fulfil both roles with greater confidence. Generally speaking, also organisations have to undergo the mindset journey from scarcity to enrichment - as the research did before.

\section{Limitations}

Measurement of leadership performance is a broad field of research per se. Assessing managers' performance by self-evaluation of behavioural patterns is obviously subject for debate and connected with bias. A 360-degree approach that includes subordinates, superiors, lateral and external evaluation could add more accuracy to the leadership assessment.

The present research forms a snapshot of a sample and cannot explain what happens during the transition phase to fatherhood. For hypothesis testing, a necessary condition for the existence of a causal link is that the independent variable precedes the dependent variable in time. When analysing cross-sectional data, as it is the case in the present study, this condition cannot be empirically verified. The chronological structure between the variables was therefore assumed and backed by literature. Longitudinal data would have ensured that the assumed temporal structure between the variables is given (Opp, 2010).

Even though we tried to avoid guiding the participants towards indicating improvement or worsening of perceived leadership behaviour, we must admit that the topic itself has the potential to lure participants into thinking predominantly about the positive effects of fatherhood. This might not be true for participants who have strong negative connotations with fatherhood, either actively or passively. Others could have a biased view due to the overall positivity of the topic of parenthood in societal debates.

Within the linear regression model, we faced the issue of strong multicollinearity between the variables net enrichment and PRC, meaning that the statistical significance of the independent variable is undermined. Nevertheless, we are confident to have enough evidence of the positive relationship between TLB and both net enrichment and PRC given the results of the Pearson correlations and regression scenarios where we alternately omitted one variable and the results of previous studies.

We suppose that participants were not entirely familiar with the definitions of the 15 leadership behaviours by Yukl. It is, therefore, possible that some misinterpreted or misunderstood the definitions as we only provided them with the short versions.

Another weakness of our study is that we did not account for the age and gender of the child/children. The age of children is very much connected to the overall weakness of our study. 
As we generally allowed male managers with at least one child to participate in the survey, we most likely also covered men that did not necessarily turn father during a period when they were active as managers. It could also be the case that children were already grown up when a participant first held a management position. Similarly, the variable "time spent with children" could have been put into context with the age of children, as we may assume that older or grown-up children require less attention in terms of time. Regarding the gender of children, previous research has found evidence that behavioural changes of parents evolve differently. For example, CEOs with daughters are said to be more other-oriented (Dahl et al., 2012). We cannot exclude that also leadership behaviours evolve differently depending on the gender constellation of the offspring. In theory, both age and gender are easy to collect. Nevertheless, data collection and interpretation becomes difficult for fathers with multiple children.

Finally, and although stated as objective, the present study focuses on males only. For reasons of comparison, it would have been of value to conduct a parallel, congruent study with female participants.

\section{Outlook}

Future research could attempt to gain access to data from social security institutions or large corporations. The former has precise data on the number, age, and gender of children and the type of profession and salary development available. Most importantly, one could literally analyse whole populations with their data in a longitudinal way. Individual corporations, on the other hand, offer smaller samples but usually have records on performance evaluations, a span of control, salary, and parenthood status. Ideally, data from both sources are combined. Longitudinal settings could also shed light on the remaining questions of whether the influence of fatherhood is rather an event-based and/or experience-based one.

Upcoming studies should aim at objectivising measurement of leadership behaviour by refining questionnaires and scales and assessing the behaviour of a manager from various perspectives (self and external assessment) and combining these results.

We have shown that parental role commitment has predictive power for relations-oriented leadership behaviour and strong multicollinearity with (net) enrichment. Besides that, it could also be of interest what role work role commitment has on leadership behaviour in parenthood.

In our present research, we have mostly dealt with "the" manager or leader even though we are aware that various personalities may be in charge of leadership functions. Future research should also consider different value structures of superiors. For example, one could follow Schwartz's (2012) four basic value ranges and test their peculiarities and connections with behavioural changes with fatherhood.

Our research did not specifically cover fatherhood by adoption. Future studies should also consider this niche and question the role and effect of (non-)biological fatherhood.

\section{Conclusion}

Previous quantitative and qualitative research has argued that parenthood positively influences overall leadership and management behaviour. Our data suggest following this path and adding important details on which individual behavioural attributes change and how. The core assumption that enrichment outweighs conflict and that the overall effect (net enrichment) leads to improvements in leadership holds true (Greenhaus \& Powell, 2006). Speaking generally, the 
earlier and the present research have opened a door that could change the way leadership and personal careers are thought and lived. However, much is left to discover and understand the conditions, backgrounds, and facilitators of leadership improvement by fatherhood in specific and parenthood in general.

\section{References}

Aaltio-Marjosola, B., \& Lehtinen, J. (1998). Male managers as fathers? Contrasting management, fatherhood, and masculinity. Human Relations, 51(2), 121-136.

Amatea, E. S., Cross, E. G., Clark, J. E., \& Bobby, C. L. (1986). Assessing the work and family role expectations of careeroriented men and women: The life role salience scales. Journal of Marriage and the Family, 48(4), 831. https://doi.org/10.2307/352576

Barnett, R. C., \& Hyde, J. S. (2001). Women, men, work, and family: An expansionist theory. American Psychologist, 56(10), 781-796. https://doi.org/10.1037//0003-066X.56.10.781

Baruch, G. K., \& Barnett, R. (1986). Role quality, multiple role involvement, and psychological well-being in midlife women. Journal of Personality and Social Psychology, 51(3), 578-585. https://doi.org/10.1037/0022-3514.51.3.578

Bass, B. M. (1990). From transactional to transformational leadership: Learning to share the vision. Organizational Dynamics, 18(3), 19-31. https://doi.org/10.1016/0090-2616(90)90061-S

Bernerth, J. B., Cole, M. S., Taylor, E. C., \& Walker, H. J. (2018). Control variables in leadership research: A qualitative and quantitative review. Journal of Management, 44(1), 131-160. https://doi.org/10.1177/0149206317690586

Bleidorn, W., Buyukcan-Tetik, A., Schwaba, T., van Scheppingen, M. A., Denissen, J. J. A., \& Finkenauer, C. (2016) Stability and change in self-esteem during the transition to parenthood. Social Psychological and Personality Science, 7(6), 560-569. https://doi.org/10.1177/1948550616646428

Cannito, M. (2020). Beyond "Traditional" and "New": An attempt of redefinition of contemporary fatherhoods through discursive practices and practices of care. Men and Masculinities, 23(3-4), 661-679. https://doi.org/10.1177/1097184X18822684

Carlson, D., Kacmar, K. M., Wayne, J. H., \& Grzywacz, J. G. (2006). Measuring the positive side of the work-family interface: Development and validation of a work-family enrichment scale. Journal of Vocational Behavior, 68(1), 131164. https://doi.org/10.1016/j.jvb.2005.02.002

Carney, K. C. W. (2004). Motherhood and management. Journal of the Motherhood Initiative for Research and Community Involvement, 6(2).

Cortina, J. M. (1993). What is coefficient alpha? An examination of theory and applications. Journal of Applied Psychology, 78(1), 98.

Cunningham, M. (2008). Changing attitudes toward the male breadwinner, female homemaker family model: Influences of women's employment and education over the lifecourse. Social Forces, 87(1), 299-323. https://doi.org/10.1353/sof.0.0097

Dahl, M. S., Dezső, C. L., \& Ross, D. G. (2012). Fatherhood and managerial style. Administrative Science Quarterly, 57(4), 669-693. https://doi.org/10.1177/0001839212466521

Dermott, E., \& Miller, T. (2015). More than the sum of its parts? Contemporary fatherhood policy, practice and discourse. Families, Relationships and Societies, 4(2), 183-195. https://doi.org/10.1332/204674315X14212269138324

Dumas, T. L., \& Stanko, T. L. (2017). Married with children: How family role identification shapes leadership behaviors at work. Personnel Psychology, 70(3), 597-633.

Edwards, J. R., \& Rothbard, N. P. (2000). Mechanisms linking work and family: Clarifying the relationship between work and family constructs. The Academy of Management Review, 25(1), 178-199. https://doi.org/10.2307/259269

Fischer, S. M., \& Kotai-Szarka, K. (2006). Vereinbarkeit von Familie und Beruf unter besonderer Berücksichtigung männerspezifischer Bedürfnisse aus der Sicht der Arbeitgeber (Unternehmer, Manager) und Arbeitnehmer (Mitarbeiter). Zukunft soziales Österreich. [Combining family and work with special consideration of male-specific needs from the perspective of employers (entrepreneurs, managers) and employees (co-workers). Future Social Austria.]. Bundesministerium für Soziale Sicherheit Generationen und Konsumentenschutz Männerpolitische Grundsatzabt. Sektion V Abt. 6.

Genesoni, L., \& Tallandini, M. A. (2009). Men's psychological transition to fatherhood: An analysis of the literature, 1989 2008. Birth, 36(4), 305-318. https://doi.org/10.1111/j.1523-536X.2009.00358.x 
Goode, W. J. (1960). A theory of role strain. American Sociological Review, 25(4), 483. https://doi.org/10.2307/2092933

Grau Grau, M. (2017). Work-Family Enrichment Experiences among Working Fathers: Evidence from Catalonia (Doctoral dissertation). Retrieved from https://era.ed.ac.uk/handle/1842/23544.

Graves, L. M., Ohlott, P. J., \& Ruderman, M. N. (2007). Commitment to family roles: Effects on managers' attitudes and performance. The Journal of Applied Psychology, 92(1), 44-56. https://doi.org/10.1037/0021-9010.92.1.44

Greenhaus, J. H., \& Beutell, N. J. (1985). Sources of conflict between work and family roles (No. 1). Academy of management. Academy of Management Review, 10.

Greenhaus, J. H., \& Brummelhuis, L. L. ten. (2013). Models and frameworks underlying work-life research. In D. A. Major \& R. J. Burke (Eds.), Elgar original reference. Handbook of work-life integration among professionals: Challenges and opportunities (pp. 14-34). Edward Elgar Publishing. https://doi.org/10.4337/9781781009291.00010

Greenhaus, J. H., \& Powell, G. N. (2006). When work and family are allies: A theory of work-family enrichment. Academy of Management Review, 31(1), 72-92. https://doi.org/10.2307/20159186

Hansen, K. (2018). Warum gute Mütter und Väter die besseren Vorstände sind [Why good fathers are better executives.]. https://www.handelsblatt.com/meinung/gastbeitraege/expertenrat/hansen/expertenrat-klaus-hansen-warum-gute-muetterund-vaeter-die-besseren-vorstaende-sind/22789816.html

Jaskiewicz, P., Combs, J. G., Shanine, K. K., \& Kacmar, K. M. (2017). Introducing the family: A review of family science with implications for management research. Academy of Management Annals, 11(1), 309-341. https://doi.org/10.5465/annals.2014.0053

Jokela, M., Kivimäki, M., Elovainio, M., \& Keltikangas-Järvinen, L. (2009). Personality and having children: A two-way relationship. Journal of Personality and Social Psychology, 96(1), 218-230. https://doi.org/10.1037/a0014058

Kacmar, K. M., Crawford, W. S., Carlson, D. S., Ferguson, M., \& Whitten, D. (2014). A short and valid measure of workfamily enrichment. Journal of Occupational Health Psychology, 19(1), 32-45. https://doi.org/10.1037/a0035123

Kotter, J. P. (1990). What leaders really do Harvard business review on leadership. Boston, MA: Harvard Business School.

Kotterman, J. (2006). Leadership versus management: What's the difference? The Journal for Quality and Participation, 29(2), 13-17. https://search.proquest.com/docview/219091679?accountid=28016

Lapierre, L. M., Li, Y., Kwan, H. K., Greenhaus, J. H., DiRenzo, M. S., \& Shao, P. (2018). A meta-analysis of the antecedents of work-family enrichment. Journal of Organizational Behavior, 39(4), 385-401. https://doi.org/10.1002/job.2234

Marks, S. R. (1977). Multiple Roles and role strain: Some notes on human energy, time and commitment. American Sociological Review, 42(6), 921. https://doi.org/10.2307/2094577

Matthews, R. A., Kath, L. M., \& Barnes-Farrell, J. L. (2010). A short, valid, predictive measure of work-family conflict: Item selection and scale validation. Journal of Occupational Health Psychology, 15(1), 75-90. https://doi.org/10.1037/a0017443

Nunes-Costa, R., Lopes, C., \& Leite, Â. (2020). Parenting and management skills: The mediator role of empathy. Scandinavian Journal of Psychology. Advance online publication. https://doi.org/10.1111/sjop.12624

Opp, K. D. (2010). Kausalität als Gegenstand der Sozialwissenschaften und der multivariaten Statistik In C. Wolf (Ed.), Handbuch der sozialwissenschaftlichen Datenanalyse (pp. 9-38). [Handbook of Social Science Data Analysis]. VS Verlag für Sozialwissenschaften. https://doi.org/10.1007/978-3-531-92038-2_2

Ruderman, M. N., Ohlott, P. J., Panzer, K., \& King, S. N. (2002). Benefits of multiple roles for managerial women. Academy of Management Journal, 45(2), 369-386. https://doi.org/10.2307/3069352

Schwartz, S. H. (2012). An overview of the Schwartz theory of basic values. Online Readings in Psychology and Culture, 2(1). https://doi.org/10.9707/2307-0919.1116

Sieber, S. D. (1974). Toward a theory of role accumulation. American Sociological Review, $39(4), 567$. https://doi.org/10.2307/2094422

Specht, J., Egloff, B., \& Schmukle, S. C. (2011). Stability and change of personality across the life course: The impact of age and major life events on mean-level and rank-order stability of the Big Five. Journal of Personality and Social Psychology, 101(4), 862-882. https://doi.org/10.1037/a0024950

van Scheppingen, M. A., Jackson, J. J., Specht, J., Hutteman, R., Denissen, J. J. A., \& Bleidorn, W. (2016). Personality trait development during the transition to parenthood. Social Psychological and Personality Science, 7(5), 452-462. https://doi.org/10.1177/1948550616630032

Yukl, G. (2012). Effective leadership behavior: What we know and what questions need more attention. Academy of Management Perspectives, 26(4), 66-85.

Zaleznik, A. (1977). Managers and leaders: Are they different. Harvard Business Review. 


\section{Acknowledgements}

Not applicable.

\section{Disclosure Statement}

No potential conflict of interest was reported by the authors.

\section{Funding Acknowledgements}

Not applicable.

\section{Open Access}

The International Journal of Organizational Leadership publishes open access articles under the terms of the Creative Commons Attribution (CC BY) License, which permits use, distribution, and reproduction in any medium, provided the original work is properly cited. 